Jurnal Olahraga \& Kesehatan Indonesia

Volume 1 Nomor 1 (2020)

E-ISSN: 2747-061X

available online at https://jurnal.stokbinaguna.ac.id/index.php/jok

\title{
PROFIL KETERAMPILAN SHOOTING FREE THROW ATLET BOLA BASKET
}

\author{
Welly Angraini Putri Apifa ${ }^{1}$, Ilham ${ }^{2}$, David Iqroni ${ }^{3}$ * \\ ${ }^{123}$ Universitas Jambi, Jambi, Indonesia, 36361 \\ *Coressponding Author: davidiqroni21@gmail.com
}

\begin{tabular}{|c|c|}
\hline Keterangan & Abstrak \\
\hline $\begin{array}{c}\text { Rekam Jejak: } \\
\text { Received, Oktober } 2020 \\
\text { Revised, November } 2020 \\
\text { Accepted, Desember } 2020\end{array}$ & $\begin{array}{l}\text { Permainan bola basket adalah salah satu cabang olahraga yang termasuk popular } \\
\text { dan banyak digemari masyarakat Indonesia. Permainan bola basket dimainkan oleh } \\
2 \text { tim yang masing-masing tim terdiri dari } 5 \text { pemain, jenis permainan ini bertujuan } \\
\text { untuk mencari angka/poin sebanyak-banyaknya dengan cara memasukan bola ke } \\
\text { ring basket lawan dan mencegah lawan untuk mendapat angka. Penelitian ini } \\
\text { bertujuan untuk mengetahui Keterampilan Shooting Free Throw Bola Basket Club }\end{array}$ \\
\hline $\begin{array}{l}\text { Kata Kunci: } \\
\text { Keterampilan Shooting Free } \\
\text { Throw, Atlet, Bola Basket }\end{array}$ & $\begin{array}{l}\text { Lima Basketball Putri Kota Jambi. Penelitian yang dilakukan menggunakan } \\
\text { analisis statistik deskriptif. Hasil penelitian pada keterampilan Shooting Free } \\
\text { Throw Bola Basket dari } 12 \text { Atlet, dimana } 8 \text { Atlet dengan persentase } 66.67 \% \text { dalam } \\
\text { kategori Sangat Baik (SB), sedangkan } 4 \text { Atlet dengan persentase } 33.3 \% \text { dalam } \\
\text { kategori Baik (B). Berdasarkan hasil yang di peroleh dalam penelitian tersebut, } \\
\text { dapat disimpulkan bahwa keterampilan shooting free throw Atlet Bola Basket Club } \\
\text { Lima Basketball Putri Kota Jambi Sangat Baik. }\end{array}$ \\
\hline
\end{tabular}




\section{PENDAHULUAN}

Olahraga bola basket bukan lagi merupakan olah raga yang awam bagi masyarakat Indonesia, khususnya para pelajar baik itu SMP, SMA, mahaatlet, dan bahkan mereka yang sudah berkeluarga. Hal ini dikarenakan tidak lepas dari banyaknya kompetisi bola basket di Indonesia, maha atlet (Campus League), pelajar DBL (Deteksi Basketball League), dan lain sebagainya, hal ini sejalan dengan pemerintah yang telah mencanangkan tekad, yaitu memasyarakatkan olahraga dan mengolahragakan masyarakat. Sehingga dimaksudkan agar masyarakat gemar berolahraga. Di wilayah Jambi, banyaknya fasilitas yang dibangun dan berbagai kejuaraan yang telah digelar, merupakan bukti bahwa olahraga bola basket mendapat tempat di kalangan masyarakat Provinsi Jambi. Melihat perkembangan olahraga bola basket pada pelajar di wilayah Jambi, masih banyak ekstrakulikuler yang memerlukan pembinaan, hal ini dikarenakan olahraga bola basket termasuk olahraga yang kompleks gerakannya, artinya gerakannya terdiri dari gabungan unsur-unsur yang terkoordinasi secara rapi sehingga memainkan bola dengan baik. Menguasai teknik melempar, menangkap, menggiring bola, dan menembak dengan baik. Oleh karena itu penguasaan terhadap teknik dasar yang benar akan menunjang kemampuan bermain. Pada hakikatnya olahraga bola basket adalah permainan dengan tujuan memasukkan bola keranjang lawan sebanyak mungkin, dan melakukan pertahanan terhadap serangan lawan agar keranjangnya tidak kemasukan bola. Menguasai teknik dasar dengan baik sangat penting guna dapat mengendalikan bola dengan baik. Teknik tersebut terbagi menjadi teknik melempar dan menangkap, teknik menggiring bola, teknik gerak berporos, teknik menembak, dan teknik merayah. Menembak bola ke keranjang lawan merupakan tujuan akhir selama bermain bola basket. Tim yang lebih banyak melakukan tembakan dan masuk ke keranjang lawan, tim itulah yang dinyatakan pemenang dalam sebuah pertandingan bola basket. Tembakan adalah kunci utama dan sasaran akhir yang dapat menentukan keberhasilan dalam olahraga bola basket selalu ditentukan oleh keberhasilan dalam menembak. Teknik yang benar perlu dilakukan untuk memperoleh keberhasilan dalam menembak.

Shooting merupakan salah satu penunjang seseorang untuk bisa memiliki teknik dasar permainan memasukkan bola ke arah ring yang baik sehingga mampu untuk melakukan gerakan shooting dengan baik dan benar. Shooting adalah keahlian yang sangat penting di dalam olahraga bola basket. Teknik dasar seperti passing, dribbling, dan rebound mungkin mengantar atlet memperoleh peluang besar membuat skor, tapi tetap saja atlet harus mampu melakukan tembakan. Dalam olahraga bola basket free throw (lemparan bebas) memberikan andil yang sangat besar terhadap kemenangan suatu regu. Tetapi pada kenyataannya banyak pemain yang kurang memaksimalkan free throw (lemparan bebas) tersebut dalam pertandingan. Free throw (lemparan bebas) mempunyai peluang yang besar untuk menjadi nilai karena dilakukan tanpa ada lawan yang menghalangi. Free throw (lemparan bebas) perlu dilatih secara teratur, sehingga pemain memiliki keterampilan free throw (lemparan bebas) yang baik. Namun jika latihanlatihan yang biasa dilatihkan kepada pemain dewasa atau professional diberikan kepada pemain pemula hal ini mungkin akan membuat para pemain pemula merasa kesulitan dalam beradaptasi dengan sistem motoriknya. Hal tersebut dapat membuat para pemain pemula merasa bosan, tidak bersemangat dan yang lebih berbahaya adalah para pemain tidak mau berlatih lagi. Maka dari itu diperlukan latihan yang di modifikasi dengan baik dan tepat agar sesuai dengan perkembangan mental, psikis, maupun motoriknya.

Shooting free throw adalah tembakan yang didapatkan dari pelanggran yang di lakukan oleh tim lawan, Shooting free throw atau lemparan bebas adalah percobaan mencetak poin tanpa rintangan dengan menembak dari belakang garis lemparan bebas (secara informal dikenal sebagai garis pelanggaran (foul line atau charity stripe), sebuah garis yang terletak di ujung area terlarang. lemparan bebas umumnya diberikan setelah pelanggaran terhadap penembak oleh tim lawan. Setiap lemparan bebas yang sukses bernilai satu poin. Suksesnya dalam melakukan 
lemparan bebas memerlukan keahlian, kebiasaan, konsentrasi dan keyakinan, kebiasaan, rileks dan irama mendukung konsentrasi dan keyakinan diri, sehingga sangat penting sekali bagi pemain basket untuk berlatih agar dapat menguasainnya. Karena masuk tidaknya tembakan (shooting) bukanlah suatu kebetulan atau keberuntungan belaka. Shooter yang handal merupakan hasil dari latihan bukan dari lahir.

\section{METODE}

Tempat penelitian yang digunakan untuk melakukan tes dalam penelitian ini adalah Lapangan Garuda Putih (gapu) Kota Jambi. Penelitian ini dilaksanakan dalam waktu 3 kali pertemuan. Metode yang digunakan dalam penelitian adalah deskriptif Arikunto (2010) bahwa penelitian deskriptif adalah penelitian yang tidak bermaksud untuk menguji hipotesis tertentu tetapi hanya menggambarkan apa adanya tentang sesuatu variabel, gejala keadaan tertentu. Tujuan dalam penelitian ini adalah untuk mengetahui keterampilan shooting free throw bola basket Club Lima Baskteball Putri Kota Jambi yang diambil sebagai sampel dengan serangkaian tes yang direncanakan. Populasi adalah wilayah generalisasi yang terdiri atas objek/subjek yang mempunyai kualitas dan karakteristik tertentu yang ditetapkan oleh peneliti untuk dipelajari dan kemudian ditarik kesimpulan. Populasi adalah keseluruhan subjek yang ingin diteliti dan menjadi sasaran generalisasi hasil-hasil penelitian, baik anggota sampel maupun diluar sampel. Jadi populasi bukan hanya seorang tetapi ada objek dan benda-benda alam yang lain. Populasi bukan sekedar jumlah yang ada pada objek/subjek yang dipelajari, tetapi meliputi seluruh karakteristik/sifat yang dimiliki oleh subjek/objek. Tapi, satu orang pun dapat dijadikan sebagai populasi karena satu orang itu mempunyai berbagai karakteristik, misalnya gaya bicaranya, disiplin pribadi, hobinya, cara bergaulnya dan lain-lain. Dari penjelasan diatas bahwa populasi adalah berkelompok yang akan menjadi objek penelitian. Objek pada penelitian ini adalah Club Lima Basketball Putri Kota Jambi sebanyak 12 atlet. Apabila subjeknya kurang dari 100 lebih baik diambil semua, sehingga penelitiannya merupakan penelitian populasi. Selanjutnya, jika subjeknya lebih dari 100 dapat diambil antara 10 sampa $15 \%$ atau 20 sampai $25 \%$ dari populasi. Maka dalam penelitian ini atlet dengan kriteria 17-19 tahun. Sampel dari penelitian ini berjumlah 12 atlet Club Lima Basketball Putri Kota Jambi.

Variabel secara sederhana dapat diartikan sebagai ciri individu, objek, gejala, dan peristiwa yang dapat di ukur secara kualitatif atau kuantitatif. Variabel penelitian ini hanya terdiri dari variabel terikat saja, yaitu keterampilan Shooting Free Throw Bola Basket. Jenis data yang digunakan pada penelitian ini adalah data primer yang di peroleh dari tes keterimpilan shooting free throw. Sumber data yang digunakan pada penelitian ini adalah Data primer di peroleh dari tes keterampilan melakukan shooting free throw dengan cara melihat teknik shooting free throw yang benar di lakukan oleh atlet. Instrumen artinya sarana penelitian berupa seperangkat tes untuk mengumpulkan data sebagai bahan pengolahan, instrumen yang digunakan dalam penelitian ini adalah tes keterampilan shooting free throw pada atlet Club Lima Baskteball Putri Kota Jambi. Dan untuk observasi alat yang diperlukan dalampenelitian, yaitu lapangan basket yang datar dan tidak licin, bola basket, peluit, dan alat tulis. Untuk menganalisis tingkat keberasilan keterampilan shooting free throw atlet Club Lima Basketball Putri Kota Jambi setelah proses latihan setiap siklusnya di lakukan dengan memberi evaluasi berupa kesempatan untuk melakukan tes keterampilan shooting free throw kembali. Analisis ini dihitung dengan menggunakan statistika sederhana. Untuk menilai tes keterampilan shooting free throw dilakukan dengan menjumlahkan nilai yang diperoleh atlet, yang selanjutnya dibagi dengan jumlah atlet yang mengikuti tes keterampilan shooting free throw sehingga diperoleh nilai rata-rata tes keterampilan yang di rumuskan sebagai berikut: 


$$
\mathrm{X}=\frac{\sum \mathrm{X}}{\sum \mathrm{N}}
$$

Keterangan:

$\mathrm{X} \quad=$ Nilai rata-rata

$\Sigma \mathrm{X} \quad=$ Jumlah nilai

$\Sigma \mathrm{N} \quad=$ Jumlah atlet

Sesuai dengan permasalahan dan tujuan penelitian, maka data yang di peroleh akan di sajikan dengan apa adanya yang berkenaan dengan faktor keadaan variabel dan fenomena yang terjadi saat penilaian berlangsung di lapangan. Peneliti menggunakan teknik dalam mengolah data dengan menggunakan rumus persentase. Apabila suatu penelitian bertujuan menggambarkan atau menemukan sesuatu sebagaimana adanya, maka teknik analisis yang di butuhkan cukup dengan penghitungan persentase.Analisa data dalam penelitian keterampilan shooting free throw atlet Club Lima Basketball Putri Kota Jambi, dilakukan dengan cara deskriptif kuantitatif. Analisa data untuk membuat distribusi frekuensi kondisi fisik dilakukan dengan cara deskriptif kuantitatif yang mengacu dari Tes Keterampilan shooting free throw untuk atlet putri. Koefisien korelasi parsial dimaksudkan untuk mencari tahu seberapa kuat hubungan salah satu atau beberapa variabel bebas terhadap variabel terikat secara parsial, tidak simultan atau bersama-sama.

Apabila data telah dikumpulkan, langkah selanjutnya adalah menganalisis data sehingga dari data tesebut dapat diambil suatu kesimpulan. Pada penelitian ini, analisis statistik yang digunakan adalah teknik deskriptif dengan presentase, dan untuk mengetahui keterampilan shooting free throw atlet Club Lima Basketball Putri Kota Jambi. Setelah data dikelompokkan dalam setiap kategori, kemudian mencari presentase masing-masing data. Frekuensi relatif dikatakan relatif sebab frekuensi yang disajikan di sini bukanlah frekuensi-frekuensi yang sebenarnya, melainkan frekuensi yang dituangkan dalam bentuk angka (persen), sehingga untuk menghitung presentase responden digunakan rumus sebagai berikut:

Keterangan:

$$
P=\frac{F}{N} 100 \%
$$

$\begin{array}{ll}\mathrm{P} & =\text { Pesentase } \\ \mathrm{F} & =\text { Frekuensi } \\ \mathrm{N} & =\text { Jumlah }\end{array}$

\section{HASIL \& PEMBAHASAN}

Data empiris yang diperoleh di lapangan melalui hasil tes dan pengukuran yang terdiri atas tahap awal, persiapan, pelaksanaan, pelepasan dan tahap akhir dan keterampilan shooting free throw bola basket Club Lima Basketball Putri Kota Jambi, selanjutnya dianalisis dengan menggunakan teknik statistik deskriptif dan statistik inferensial. Analisis data secara deskriptif dimaksudkan untuk mendapatkan gambaran umum data penelitian, kemudian dilanjutkan dengan pengujian persyaratan analisis yaitu uji normalitas data. Sedangkan analisis data secara inferensial dimaksudkan untuk mendapatkan hasil pengujian hipotesis yang diajukan dalam penelitian ini. Data keterampilan shooting free throw meliputi tahap awal, persiapan, pelaksanaan, pelepasan dan tahap akhir serta keterampilan shooting free throw bola basket Club Lima Basketball Putri Kota Jambi. Adapun rangkuman data tersebut dituangkan dalam tabel berikut ini: 
Tabel 1. Rangkuman Hasil Analisis Deskriptif Data

\begin{tabular}{ccccccc}
\hline & Tahap Awal & Persiapan & Pelaksanaan & Pelepasan & Tahap Akhir & Total \\
$\mathrm{N}$ & 20 & 20 & 20 & 20 & 20 & 20 \\
Sum & 30 & 74 & 69 & 49 & 55 & 277 \\
Mean & 2.5 & 6.17 & 5.75 & 4.08 & 4.58 & 23.08 \\
St. Dev & 0.79 & 1.03 & 1.21 & 1.08 & 0.79 & 4.48 \\
Varian & 0.63 & 1.06 & 1.47 & 1.17 & 0.62 & 20.08 \\
Min & 1 & 4 & 4 & 3 & 3 & 15 \\
Max & 3 & 7 & 7 & 6 & 5 & 28 \\
\hline
\end{tabular}

Berdasarkan tabel tersebut, berikut ini rangkuman hasil analisis deskriptif data keterampilan shooting free throw yang dijabarkan sebagai berikut:

- Data tahap awal mendapatkan rata-rata $($ mean $)=2.5$ poin, dari 12 sampel dengan jumlah nilai secara keseluruhan (sum) sebanyak 30 poin, Untuk nilai simpangan baku (standar deviasi $)=0.79$ dengan poin terendah $($ minimum $) 1$ poin sedangkan poin tertinggi $($ maximum $)$ 3 poin.

- Data tahap persiapan mendapatkan rata-rata $($ mean $)=6.17$ poin, dari 12 sampel dengan jumlah nilai secara keseluruhan (sum) sebanyak 74 poin, Untuk nilai simpangan baku $($ standar deviasi $)=1.03$ dengan poin terendah $($ minimum $) 4$ poin sedangkan poin tertinggi (maximum) 7 poin.

- Data pelaksanaan mendapatkan rata-rata $(m e a n)=5.75$ poin, dari 12 sampel dengan jumlah nilai secara keseluruhan (sum) sebanyak 69 poin, Untuk nilai simpangan baku (standar deviasi $)=1.31$ dengan poin terendah $($ minimum $) 4$ poin sedangkan poin tertinggi $($ maximum $)$ 7 poin.

- Data pelepasan mendapatkan rata-rata $($ mean $)=4.08$ poin, dari 12 sampel dengan jumlah nilai secara keseluruhan (sum) sebanyak 49 poin, Untuk nilai simpangan baku (standar deviasi $)=1.08$ dengan poin terendah $($ minimum $) 3$ poin sedangkan poin tertinggi $($ maximum $)$ 6 poin.

- Data tahap akhiran mendapatkan rata-rata $($ mean $)=4.58$ poin, dari 12 sampel dengan jumlah nilai secara keseluruhan (sum) sebanyak 55 poin, Untuk nilai simpangan baku (standar deviasi $)=0.79$ dengan poin terendah $($ minimum) 3 poin sedangkan poin tertinggi $($ maximum $)$ 6 poin.

- Data Keterampilan shooting free throw mendapatkan rata-rata (mean) $=23.08$ poin, dari 12 sampel dengan jumlah nilai secara keseluruhan (sum) sebanyak 277 poin, Untuk nilai simpangan baku (standar deviasi) $=4.48$ dengan poin terendah (minimum) 15 poin sedangkan poin tertinggi (maximum) 28 poin.

- Hasil yang telah diperoleh pada penelitian tentang tes keterampilan shooting free throw yang terdiri dari tahap awal, persiapan, pelaksanaan, pelepasan, dan tahap akhir dituangkan dalam bentuk persentase untuk mendapatkan kategori frekuensi setiap variabel yang diperoleh.

Tabel 2. Rangkuman Hasil Analisis Deskriptif

\begin{tabular}{cccc}
\hline Interval & Klasifikasi & Frekuensi & Presentasi \\
$22-28$ & Sangat Baik (SB) & 8 & $66.67 \%$ \\
$15-21$ & Baik (B) & 4 & $33.3 \%$ \\
$8-14$ & Cukup (C) & 0 & $0 \%$ \\
$0-7$ & Kurang (K) & 0 & $0 \%$ \\
\hline
\end{tabular}

Berdasarkan Tabel 2 di atas tentang hasil penelitian keterampilan shooting free throw yang diperoleh pada atlet bola basket Club Lima Basketball Putri Kota Jambi, bahwa dari 12 sampel ternyata yang memiliki klasifikasi Baik Sekali sebanyak 8 atlet (66.67\%), klasifikasi baik 
sebanyak 4 atlet (33.3\%). Dengan demikian, dapat disimpulkan bahwa hasil tes keterampilan shooting free throw yang diperoleh pada atlet bola basket Club Lima Basketball Putri Kota Jambi yang mengikuti latihan di Club Lima dapat dikategorikan Baik Sekali dengan hasil ratarata 23.08 .

Dilihat dari analisis data yang diperoleh, dalam penelitian ini diharapkan melahirkan suatu kesimpulan yang sesuai dengan data yang diperoleh. Dengan demikian, kesimpulan yang diambil nantinya akan memperlihatkan gambaran langsung dari data yang diharapkan selama penelitian ini dilakukan. Adapun hasil penelitian yaitu keterampilan shooting free throw yang diperoleh pada atlet bola basket Club Lima Basketball Putri Kota Jambi termasuk dalam kategori sangat baik. Apabila hasil penelitian ini dikaitkan dengan teori dan kerangka berpikir yang mendasarinya, maka pada dasarnya hasil penelitian ini mendukung dan memperkuat teori dan hasil-hasil penelitian terdahulu, bahwa keterampilan shooting free throw yang baik dapat membuat atlet menjadi lebih terampil dalam artian sudah mendapatkan gerakan yang sistematis, dimana hasil penelitian tes keterampilan shooting free throw yang diperoleh pada atlet bola basket Club Lima Basketball Putri Kota Jambi, bahwa dari 12 sampel atlet ternyata yang memiliki klasifikasi Baik Sekali sebanyak 8 atlet (66.67\%), klasifikasi baik sebanyak 4 atlet (33.3\%). Dengan demikian, dapat disimpulkan bahwa hasil keterampilan shooting free throw yang diperoleh pada atlet bola basket Club Lima Basketball Putri Kota Jambi dapat dikategorikan Sangat Baik dengan hasil rata-rata 23.08. Kondisi fisik merupakan unsur penting dan menjadi dasar (pondasi) dalam mengembangkan teknik, taktik, dan mental. Seorang atlet harus memiliki kondisi fisik yang baik, untuk mengoptimalkan setiap pertandingan yang dilaksanaan. Dari berbagai pendapat yang dikemukakan, dapat dikatakan bahwa kebugaran jasmani yang dimiliki atlet juga akan menjadi pendukung dalam mengembangkan keterampilan shooting free throw bermain bola basket, sebab faktor dominan yang mempengaruhi tingkat keberhasilan keterampilan adalah bakat dan pengalaman yang diperoleh dari lingkungan, berupa latihan secara rutin dan berkesinambungan.

\section{SIMPULAN}

Berdasarkan hasil penelitian yang telah dilakukan tentang keterampilan shooting free throw yang diperoleh pada atlet bola basket Club Lima Basketball Putri Kota Jambi, bahwa dari 12 sampel ternyata yang memiliki klasifikasi Baik Sekali sebanyak 8 atlet (66.67\%), dan klasifikasi Baik sebanyak 4 atlet (33.3\%). Dengan demikian, dapat disimpulkan bahwa hasil tes keterampilan shooting free throw yang diperoleh pada atlet bola basket yang mengikuti latihan di Club Lima Basketball Putri Kota Jambi dapat dikategorikan Baik Sekali dengan hasil rata-rata 23.08.

\section{DAFTAR PUSTAKA}

Arikunto, Suharsimi. (2006). Metode Penelitian Kualitatif. Jakarta: Bumi Aksara. Arsil. (2009). Tes Pengukuran Dan Evaluasi Pendidikan Jamani Dan Olahraga. Malang: Wineka Media.

Bafirman. (2012). Pembentukan Kondisi Fisik. Padang: Bahan Ajar.

Darmawan, Deni. (2014). Metode Penelitian Kuantitatif. Bandung: PT Remaja Rosdakarya.

Evelyn, Pearce. (2005). Anatomi Dan Fisiologi Untuk Medis. Jakarta: PT Gramedia Pustaka Utama.

Keven, Prusak. (2007). Permainan Bola Basket. Klaten: PT Intan Sejati. 
Kosasih. (2008). Tafsiran Hasil Pemeriksaan Laboratorium Klinik Edisi Kedua. Tangerang: Karisma Publishing Group.

Oliver. (2004). Basketball. Lamongan: Suka Karya.

Sudjana. (2002). Metode Statiska. Bandung: Tarsito.

Soedikun. (1999). Olahraga Bola Basket. Surakarta: PT Bina Nusa.

Sugiyono. (2016). Metode Penelitian Kuantitatif. Kualitatif Dan R\&D. Bandung:

Alfabeta.

Wissel, Hall. (2000). Bola Basket Dilengkapi Dengan Program Pemahiran Teknik Dan Taktik. Jakarta: PT. Raja Grafindo Persada. 